\title{
Validation of a Multiplex Assay for Measuring Specific IgG4
}

\author{
Sung-Ryeol Kim, ${ }^{1,2}$ Kyung Hee Park ${ }^{2,3}$, Ji Eun Lee ${ }^{4}$, Bum Joon Kim4, Kook Jin Lim4, and Jung-Won Park ${ }^{2,3}$ \\ ${ }^{1}$ Department of Internal Medicine, Yongin Severance Hospital, Yonsei University College of Medicine, Yongin; \\ ${ }^{2}$ Institute of Allergy, Yonsei University College of Medicine, Seoul; \\ ${ }^{3}$ Division of Allergy and Immunology, Department of Internal Medicine, Yonsei University College of Medicine, Seoul; \\ ${ }^{4}$ ProteomeTech Inc., Seoul, Korea.
}

\begin{abstract}
Purpose: Specific IgG4 (sIgG4) increases with allergen specific immunotherapy and may reflect a state of immune tolerance in food allergy. While ImmunoCAP ${ }^{\circledR}$ has been widely used to measure sIgG4 to a single allergen, PROTIA ${ }^{\mathrm{TM}}$ Specific IgG $4^{\circledR}$ has been designed as a multiplex assay for measuring sIgG4. This study sought to validate this assay in comparison to ImmunoCAP ${ }^{\circledR}$.

Materials and Methods: Measurements of sIgG4 were compared between PROTIA ${ }^{\mathrm{TM}}$ Specific IgG4 ${ }^{\circledR}$ and ImmunoCAP ${ }^{\circledR}$ using sera from 519 allergy patients (asthma: 114, allergic rhinitis: 318, food allergy: 146) with 731 paired tests. sIgG4 was measured against nine inhalant allergens (Dermatophagoides pteronyssinus, Dermatophagoides farinae, cat dander, dog dander, birch pollen, oak pollen, ragweed pollen, mugwort pollen, and Alternaria alternata spores) and nine food allergens (egg white, casein, wheat, peanut, walnut, crab, shrimp, apple, and peach).

Results: PROTIA ${ }^{\mathrm{TM}}$ Specific IgG4 ${ }^{\circledR}$ showed $95.6 \%$ agreement rate with ImmunoCAP ${ }^{\circledR}$ in the positivity comparison. For sIgG4 positivity to each individual allergen, an agreement rate of more than $84.8 \%$ was observed. In Cohen's kappa analysis, these assays displayed substantial correlations [Cohen's kappa coefficient $(\kappa) \geq 0.699$ ], except for shrimp $(\kappa=0.448)$. Furthermore, both assays displayed strong correlations in quantitative comparisons [correlation coefficients value $(\rho) \geq 0.8014$ ], except for apple $(\rho=0.6571$, $p=0.175)$. Serial dilution tests also showed consistency between the assays.

Conclusion: PROTIA ${ }^{\mathrm{TM}}$ Specific IgG4 ${ }^{\circledR}$ showed high consistency with ImmunoCAP ${ }^{\circledR}$ in measuring sIgG4. This assay is applicable to various clinical fields, including allergen immunotherapy and food allergy.
\end{abstract}

Key Words: Immunoglobulin G, immunoassay, allergens

\section{INTRODUCTION}

Immunoglobulin G (IgG) is the most common immunoglobulin, accounting for approximately $75 \%$ of all immunoglobulins in the blood. ${ }^{1}$ IgG is further subdivided into the subtypes IgG1, IgG2, IgG3, and IgG4, ${ }^{2}$ among which IgG4 accounts

\section{Received: March 26, 2020 Revised: May 6, 2020}

Accepted: May 8, 2020

Corresponding author: Jung-Won Park, MD, PhD, Division of Allergy and Immunology, Department of Internal Medicine, Yonsei University College of Medicine, 50-1 Yonsei-ro, Seodaemun-gu, Seoul 03722, Korea.

Tel: 82-2-2228-1961, Fax: 82-2-393-6884, E-mail: parkjw@yuhs.ac

\section{(C) Copyright: Yonsei University College of Medicine 2020}

This is an Open Access article distributed under the terms of the Creative Commons Attribution Non-Commercial License (https://creativecommons.org/licenses/ by-nc/4.0) which permits unrestricted non-commercial use, distribution, and reproduction in any medium, provided the original work is properly cited. for approximately $2-5 \%$ of all IgG. ${ }^{2}$ Unlike the other IgG subtypes, IgG4 is known to have non-inflammatory properties. ${ }^{3}$ It forms a bispecific monovalent antibody through Fab arm exchange, ${ }^{4}$ exhibits a limited ability to cross-link with allergens, and cannot form immune complexes. ${ }^{3,5}$ Further, it has a disrupted Clq-binding site and, thus, cannot activate complement pathways. ${ }^{6}$ It also has reduced effector function relative to other IgG subtypes. ${ }^{4}$ Furthermore, specific IgG4 (sIgG4) competes with specific IgE (sIgE) to prevent mast cell and basophil degranulation and is known as a blocking antibody. ${ }^{3}$ These unique characteristics of IgG4 make it favorable for the assessment of immunotherapy efficacy: sIgG4 levels are increased following immunotherapy and then decrease after termination of immunotherapy. ${ }^{3,7}$ In addition, sIgE/sIgG4 ratios for food allergens, such as egg, milk, and peanut, are associated with the prediction of immune tolerance to these aller- 
gens. ${ }^{8,9}$ Therefore, sIgG4 is considered as a monitoring tool of immunotherapy ${ }^{10}$ and an alternative to the double-blind placebo-controlled food challenge test (DBPCFC) for predict remission. ${ }^{11}$

Meanwhile, IgG4 can be harmful in some diseases. IgG4 is closely associated with eosinophilic esophagitis ${ }^{12}$ and is involved in the immune response of factor VIII and factor IX..$^{13,14}$ These factors can be inhibited by IgG4, and this immune reaction is associated with hemophilia. Moreover, IgG4 can reduce clinical responses to recombinant antibodies, such as adalimumab. ${ }^{15}$ Additionally, IgG4 is associated with parasite infection and IgG4-related disease. ${ }^{16,17}$ Therefore, IgG4 may be used as biomarkers for such pathologic conditions.

The ImmunoCAP ${ }^{\circledR}$ assay (Thermo Fisher Scientific, Uppsala, Sweden) has been widely used to detect sIgG4. However, ImmunoCAP ${ }^{\circledR}$ is a singleplex assay, and the cost per allergen is higher than that of a multiplex assay. Recently, PROTIA ${ }^{\mathrm{TM}}$ Specific IgG $4^{\circledR}$ (ProteomeTech Inc., Seoul, Korea), a multiplex sIgG4 assay, was developed to solve this issue. It is based on the enzyme immunoassay technique that uses nitrocellulose membrane as the solid-phase for allergen immobilization and can quantify sIgG4 against 42 important food and inhalant allergens using only $10 \mu \mathrm{L}$ of serum (Table 1 ). This study aimed to validate PROTIA ${ }^{\mathrm{TM}}$ Specific IgG4 ${ }^{\circledR}$ in comparison with ImmunoCAP ${ }^{\circledR}$.

\section{MATERIALS AND METHODS}

\section{Study participants}

Five hundred and nineteen Korean allergy patients who visited the Allergy and Asthma Center of Severance Hospital for the diagnosis and treatment of their allergic diseases from August 2013 to May 2019 were enrolled in this study. The demographic characteristics of the patients are summarized in Table 2. There were 310 males and 209 females. The mean age of the patients was $24.0 \pm 16.9$ years (mean \pm standard deviation). Three hundred and eighteen patients $(61.3 \%)$ had allergic rhinitis, 198 (38.2\%) patients had atopic dermatitis, 146 patients $(28.1 \%)$ had food allergy, and 114 patients $(22.0 \%)$ had asthma. Patients did not have other chronic diseases, including autoimmune diseases, cancer, chronic infections, or other immunerelated diseases. Blood samples were collected from all patients to perform the two diagnostic tests, PROTIA ${ }^{\mathrm{TM}}$ Specific $\operatorname{IgG} 4^{\circledR}$ and ImmunoCAP ${ }^{\circledR}$. The total number of paired tests was 731 , and the most frequently tested allergen was Dermatophagoides farinae (235), followed by Dermatophagoides pteronyssinus (176), Alternaria alternata spores (36), walnut (33), casein (31), cat dander (30), dog dander (26), egg white (24), wheat (24), peanut (23), peach (17), crab (16), shrimp (16), apple (15), birch pollen (10), oak pollen (7), ragweed pollen (7), and mugwort pollen (5). The Severance Hospital Ethical Review Board approved this study (No. 4-2017-1258), and in-
Table 1. Specific IgG4s That Can Be Quantified Using PROTIA ${ }^{\mathrm{TM}}$ Specific $\lg 4^{\circledR}$

\begin{tabular}{clcl}
\hline Number & \multicolumn{1}{c}{ Allergen } & Number & \multicolumn{1}{c}{ Allergen } \\
\hline 1 & Dermatophagoides pteronyssinus & 22 & Milk \\
\hline 2 & Dermatophagoides farinae & 23 & Casein \\
\hline 3 & Cat dander & 24 & $\alpha$-lactalbumin \\
\hline 4 & Dog dander & 25 & $\beta$-lactoglobulin \\
\hline 5 & Birch pollen & 26 & Codfish \\
\hline 6 & Oak pollen & 27 & Mackerel \\
\hline 7 & Grass pollen mix & 28 & Crab \\
\hline 8 & Ragweed pollen & 29 & Shrimp \\
\hline 9 & Mugwort pollen & 30 & Oyster \\
\hline 10 & Japanese hop pollen & 31 & Wheat \\
\hline 11 & Aspergillus fumigatus spores & 32 & Buckwheat \\
\hline 12 & Penicillium notatum spores & 33 & Rice \\
\hline 13 & Alternaria alternata spores & 34 & Soy bean \\
\hline 14 & Bee venom & 35 & Peanut \\
\hline 15 & Wasp venom & 36 & Walnut \\
\hline 16 & Cockroach & 37 & Almond \\
\hline 17 & Pork & 38 & Peach \\
\hline 18 & Beef & 39 & Apple \\
\hline 19 & Chicken & 40 & Kiwi \\
\hline 20 & Egg yolk & 41 & Mango \\
\hline 21 & Egg white & 42 & $\alpha$-Gal \\
\hline & & & \\
\hline
\end{tabular}

formed consent was obtained from all 519 patients.

\section{Serum preparation and allergen selection}

Five milliliters of whole blood was collected in a vacuum tube (Vacuette $^{\circledR}$; Greiner Bio-One GmbH, Kremsmünster, Austria) for serum separation via centrifugation at $3000 \mathrm{rpm}$ for $5 \mathrm{~min}$, and the supernatant was aliquoted into several round-bottom tubes (5-mL BD Falcon ${ }^{\mathrm{TM}}$ tubes; BD Bioscience Discovery Labware, Bedford, MA, USA), and stored at $-76^{\circ} \mathrm{C}$ until further use.

Eighteen culprit allergens were selected for measuring sIgG4: nine inhalant allergens (D. pteronyssinus, D. farinae, cat dander, dog dander, birch pollen, oak pollen, ragweed pollen, mugwort pollen, and Alternaria alternata spores) and nine food allergens (egg white, casein, wheat, peanut, walnut, crab, shrimp, apple, and peach).

\section{In vitro sIgG4 measurements}

Both PROTIA ${ }^{\mathrm{TM}}$ Specific IgG $4^{\circledR}$ and ImmunoCAP ${ }^{\circledR}$ sIgG4 assays were performed according to the manufacturers' instructions. The researcher performing the PROTIA ${ }^{\mathrm{TM}}$ Specific IgG $4^{\circledR}$ assay was blinded to the results of ImmunoCAP ${ }^{\circledR}$. The sIgG4 detection range of PROTIA ${ }^{\mathrm{TM}}$ Specific IgG $4^{\circledR}$ was $0.50-30 \mathrm{mg} /$ $\mathrm{L}$, and that of ImmunoCAP ${ }^{\circledR}$ was $0.07-30 \mathrm{mg} / \mathrm{L}$. To compare the agreement rate of these two assays, sIgG4 values $\geq 0.50$ $\mathrm{mg} / \mathrm{L}$ were regarded as positive. 
Table 2. Demographic Characteristics of the 519 Studied Subjects in Accordance with the Allergens

\begin{tabular}{|c|c|c|c|c|c|c|c|c|c|c|}
\hline \multirow{2}{*}{ Allergens } & \multirow{2}{*}{$\begin{array}{l}\text { Number of } \\
\text { samples }\end{array}$} & \multirow{2}{*}{$\begin{array}{l}\text { Male: } \\
\text { female }\end{array}$} & \multirow{2}{*}{$\begin{array}{c}\text { Age, yr } \\
\text { (mean } \pm S D)\end{array}$} & \multicolumn{3}{|c|}{ ImmunoCAP slgE } & \multicolumn{4}{|c|}{ Underlying disease } \\
\hline & & & & Positive & Negative & Not performed & AR & Asthma & AD & Food allergy \\
\hline $\begin{array}{l}\text { Dermatophagoides } \\
\text { pteronyssinus }\end{array}$ & 176 & $112: 64$ & $25.8 \pm 10.8$ & $158(89.8)$ & $4(2.3)$ & $14(8.0)$ & 164 (93.2) & $32(18.2)$ & $105(59.7)$ & $12(6.8)$ \\
\hline $\begin{array}{l}\text { Dermatophagoides } \\
\text { farinae }\end{array}$ & 235 & $146: 89$ & $29.1 \pm 13.8$ & $222(94.5)$ & $4(1.7)$ & $9(3.8)$ & 223 (94.9) & $52(22.1)$ & $7(3.0)$ & $9(3.8)$ \\
\hline Cat dander & 30 & $15: 15$ & $32.7 \pm 13.4$ & $30(100)$ & $0(0)$ & $0(0)$ & 22 (73.3) & $17(56.7)$ & $9(30.0)$ & $0(0)$ \\
\hline Dog dander & 26 & $11: 15$ & $31.4 \pm 13.5$ & 23 (88.5) & $1(3.8)$ & $2(7.7)$ & $17(65.4)$ & $16(61.5)$ & $13(50.0)$ & $0(0)$ \\
\hline Birch pollen & 10 & $8: 2$ & $19.4 \pm 7.5$ & $9(90.0)$ & $1(10.0)$ & $0(0)$ & $7(70.0)$ & $5(50.0)$ & $1(10.0)$ & $0(0)$ \\
\hline Oak pollen & 7 & $6: 1$ & $21.0 \pm 10.8$ & $4(57.1)$ & $3(42.9)$ & $0(0)$ & $4(57.1)$ & $2(28.6)$ & $1(14.3)$ & $0(0)$ \\
\hline Ragweed pollen & 7 & $4: 3$ & $45.6 \pm 10.0$ & $6(85.7)$ & $1(14.3)$ & $0(0)$ & $7(100)$ & $3(42.9)$ & $1(14.3)$ & $0(0)$ \\
\hline Mugwort pollen & 5 & $2: 3$ & $38.2 \pm 16.1$ & $2(40.0)$ & $2(40.0)$ & $1(20.0)$ & $5(100)$ & $0(0)$ & $0(0)$ & $0(0)$ \\
\hline $\begin{array}{l}\text { Alternaria alternata } \\
\text { spores }\end{array}$ & 36 & $25: 11$ & $17.0 \pm 14.3$ & $36(100)$ & $0(0)$ & $0(0)$ & 22 (61.1) & $14(38.9)$ & $7(19.4)$ & $9(25.0)$ \\
\hline Egg white & 24 & $17: 7$ & $4.8 \pm 3.8$ & $24(100)$ & $0(0)$ & $0(0)$ & $3(12.5)$ & $3(12.5)$ & $12(50.0)$ & 21 (87.5) \\
\hline Casein & 31 & 19:12 & $9.3 \pm 13.3$ & $24(77.4)$ & $7(22.6)$ & $0(0)$ & $2(6.5)$ & $5(16.1)$ & $18(58.1)$ & 28 (90.3) \\
\hline Wheat & 24 & $16: 8$ & $12.8 \pm 16.8$ & $18(75.0)$ & $6(25.0)$ & $0(0)$ & $3(12.5)$ & $0(0)$ & 8 (33.3) & $14(58.3)$ \\
\hline Peanut & 23 & $12: 11$ & $7.5 \pm 9.2$ & $20(87.0)$ & $2(8.7)$ & $1(4.3)$ & $3(13.0)$ & $3(13.0)$ & $9(39.1)$ & $15(65.2)$ \\
\hline Walnut & 33 & $17: 16$ & $8.4 \pm 4.9$ & 32 (97.0) & $1(3.0)$ & $0(0)$ & $5(14.7)$ & $4(11.8)$ & $10(29.4)$ & $15(44.1)$ \\
\hline Crab & 16 & $9: 7$ & $43.4 \pm 17.2$ & 14 (87.5) & $2(12.5)$ & $0(0)$ & $2(12.5)$ & $0(0)$ & $1(6.3)$ & $10(62.5)$ \\
\hline Shrimp & 16 & $11: 5$ & $31.9 \pm 21.5$ & $14(87.5)$ & $2(12.5)$ & $0(0)$ & 5 (31.3) & $1(6.3)$ & $1(6.3)$ & 13 (81.3) \\
\hline Apple & 15 & $9: 6$ & $31.9 \pm 20.6$ & $15(100)$ & $0(0)$ & $0(0)$ & $10(66.7)$ & $2(13.3)$ & $2(13.3)$ & $12(80.0)$ \\
\hline Peach & 17 & $8: 9$ & $23.2 \pm 14.9$ & 14 (82.4) & $2(11.8)$ & $1(5.9)$ & $4(23.5)$ & $1(5.9)$ & $4(23.5)$ & $5(29.4)$ \\
\hline Total & 731 (519 patients) & $310: 209$ & $24.0 \pm 16.9$ & $665(90.8)$ & $38(5.2)$ & $28(3.8)$ & $318(61.3)$ & $114(22.0)$ & 198 (38.2) & $146(28.1)$ \\
\hline
\end{tabular}

$A R$, allergic rhinitis; $A D$, atopic dermatitis.

Data are presented as number (\%) unless otherwise noticed.

\section{Serial dilution test}

sIgG4 levels were measured by PROTIA ${ }^{\mathrm{TM}}$ Specific IgG $4^{\circledR}$ using serial dilutions of patient sera. Sera with high IgG4 titers against D. pteronyssinus, D. farinae, cat dander, dog dander, birch pollen, or ragweed pollen were selected for this analysis. Selected serum samples were diluted one-, two-, four-, eight-, 16-, 32-, 64-, and 128-fold with immunoglobulin-depleted serum.

\section{Statistical analysis}

The positivity of sIgG4 values was compared using Cohen's kappa analysis. Cohen's kappa values $(\kappa)$ were categorized as almost perfect (0.8-1.0), substantial (0.6-0.8), moderate (0.40.6 ), fair (0.2-0.4), or poor correlations (below 0.2) ${ }^{18}$ Pearson's correlation coefficients were used for quantitative comparisons of house dust mite sIgG4, and Spearman's rank coefficient was used for quantitative comparisons of sIgG4 for other allergens. The degrees of correlation were expressed as a Pearson's correlation coefficient value (r) or Spearman's correlation coefficient value $(\rho)$. Correlation coefficient values were categorized as very strong $(0.90-1.00)$, strong $(0.70-0.89)$, moderate (0.40-0.69), weak (0.10-0.39), or negligible correlations (0.00-0.09). ${ }^{19}$ Because negative values cannot be compared, only sIgG4 values $\geq 0.50 \mathrm{mg} / \mathrm{L}$ were used for quantitative comparison. SPSS 25.0 (IBM Corp., Armork, NY, USA) was used for statistical analysis, and $p<0.05$ was considered statis- tically significant.

\section{RESULTS}

\section{Qualitative comparison between the two assays}

Comparing positivity with the cut-off level of $0.50 \mathrm{mg} / \mathrm{L}$, the agreement rate for all 731 paired tests was $95.6 \%$, with at least equal or more than $84.8 \%$ agreement rate (walnut) being observed between the two assays for each allergen (Table 3). Inhalant allergens showed high agreement rates of more than $90 \%$. Food allergens also showed high agreement rates of more than $90 \%$, except walnut (84.8\%) and shrimp (87.5\%). In the Cohen's kappa analysis, most inhalant allergens showed almost perfect correlation $(\kappa>0.8)$. Dog dander showed substantial correlation ( $\kappa=0.752)$. Most food allergens also showed almost perfect correlation, and walnut showed substantial correlation ( $\kappa=0.699)$. However, shrimp showed only moderate correlation $(\kappa=0.448)$. The $\kappa$ value could not be determined for crab because all sIgG4 titers against crab were negative.

\section{Quantitative comparison between the two assays}

The measured sIgG4 values of 12 allergens (D. pteronyssinus, $D$. farinae, cat dander, dog dander, birch pollen, ragweed pollen, egg white, casein, wheat, peanut, walnut, and peach) that 
Sung-Ryeol Kim, et al.

Table 3. Qualitative Comparison of ImmunoCAP ${ }^{\circledR}$ and PROTIA ${ }^{\mathrm{TM}}$ Specific $\lg G 4^{\circledR}$

\begin{tabular}{|c|c|c|c|c|c|c|}
\hline \multirow{2}{*}{ Allergens } & \multicolumn{2}{|c|}{ ImmunoCAP $^{\circledR}$} & \multicolumn{2}{|c|}{ PROTIA $^{\mathrm{TM}}$ Specific IgG4 ${ }^{\circledR}$} & \multirow{2}{*}{ Agreement rate (\%) } & \multirow{2}{*}{$\kappa$ value } \\
\hline & Positive (n) & Negative (n) & Positive (n) & Negative (n) & & \\
\hline Dermatophagoides pteronyssinus & 69 & 107 & 79 & 97 & 94.3 & $0.884^{\dagger}$ \\
\hline Dermatophagoides farinae & 91 & 144 & 93 & 142 & 97.4 & $0.946^{\dagger}$ \\
\hline Cat dander & 18 & 12 & 16 & 14 & 93.3 & $0.865^{\dagger}$ \\
\hline Dog dander & 21 & 5 & 21 & 5 & 92.3 & $0.752^{\dagger}$ \\
\hline Birch pollen & 5 & 5 & 5 & 5 & 100.0 & $1^{*}$ \\
\hline Oak pollen & 2 & 5 & 2 & 5 & 100.0 & $1^{*}$ \\
\hline Ragweed pollen & 6 & 1 & 6 & 1 & 100.0 & $1^{*}$ \\
\hline Mugwort pollen & 1 & 4 & 1 & 4 & 100.0 & $1^{*}$ \\
\hline Alternaria alternata spore & 1 & 35 & 1 & 35 & 100.0 & $1^{\dagger}$ \\
\hline Egg white & 12 & 12 & 12 & 12 & 100.0 & $1^{\dagger}$ \\
\hline Casein & 21 & 10 & 22 & 9 & 96.8 & $0.924^{\dagger}$ \\
\hline Wheat & 15 & 9 & 15 & 9 & 100.0 & $1^{\dagger}$ \\
\hline Peanut & 7 & 16 & 9 & 14 & 91.3 & $0.810^{\dagger}$ \\
\hline Walnut & 12 & 21 & 17 & 16 & 84.8 & $0.699^{\dagger}$ \\
\hline Crab & 0 & 16 & 0 & 16 & 100.0 & $\mathrm{~N} / \mathrm{A}$ \\
\hline Shrimp & 1 & 15 & 3 & 13 & 87.5 & $0.448^{*}$ \\
\hline Apple & 6 & 9 & 7 & 8 & 93.3 & $0.865^{\dagger}$ \\
\hline Peach & 11 & 6 & 10 & 7 & 94.1 & $0.876^{\dagger}$ \\
\hline Total & 299 & 432 & 319 & 412 & 95.6 & $0.910^{\dagger}$ \\
\hline
\end{tabular}

$\mathrm{N} / \mathrm{A}$, not applicable.

$\kappa=$ Cohen's kappa coefficient, $\kappa$ values were categorized as almost perfect $(0.8-1.0)$, substantial $(0.6-0.8)$, moderate $(0.4-0.6)$, fair $(0.2-0.4)$, or poor correlations $(<0.2)$. ${ }^{*} p<0.05,{ }^{\dagger} p<0.001$.

were positive in both assays are shown in Fig. 1. The sIgG4 values of other allergens that had only a few cases (oak pollen, mugwort pollen, Alternaria alternata spores, shrimp, and apple) are shown in Supplementary Fig. 1 (only online). The values of the two assays showed consistent tendencies, and correlation analysis between the two assays also showed a significant correlation (Table 4). Inhalant allergens showed more than strong correlation ( $\mathrm{r}$ or $\rho>0.7$ ). Food allergens also showed more than strong correlation, except for apple (moderate, $\rho=0.6571, p=0.175$ ). Oak pollen, mugwort pollen, Alternaria alternata spores, crab, and shrimp could not be assessed owing to very few positive pairs of results.

\section{Serial dilution test}

Each serum sample with positive sIgG4 against $D$. pteronyssinus $(12.3 \mathrm{mg} / \mathrm{L})$, D. farinae $(12.0 \mathrm{mg} / \mathrm{L})$, cat dander $(19.4 \mathrm{mg} /$ $\mathrm{L})$, dog dander $(7.3 \mathrm{mg} / \mathrm{L})$, birch pollen $(14.5 \mathrm{mg} / \mathrm{L})$, and ragweed pollen $(10.87 \mathrm{mg} / \mathrm{L})$ was serially diluted with immunoglobulin-depleted serum. The decreasing concentration-dilution curves for sIgG4 values are illustrated in Fig. 2. The average reduction rates based on the two-fold dilution for sIgG4 were around 50\%: D. pteronyssinus (51\%), D. farinae (48\%), cat dander (51\%), dog dander (54\%), birch pollen (53\%), and ragweed pollen $(50 \%)$. When values were lower than the measurable value, tests showing negative results were repeated.

\section{DISCUSSION}

This study is the first, to our knowledge, to validate the sIgG4 measurement ability of PROTIA ${ }^{\mathrm{TM}}$ Specific IgG4 ${ }^{\circledR}$. This assay showed a high agreement with ImmunoCAP ${ }^{\circledR}$ for the qualitative and quantitative measurements of sIgG4. Furthermore, the serial dilution test confirmed the measurement consistency of this assay. The PROTIA ${ }^{\mathrm{TM}}$ Specific IgG4 ${ }^{\circledR}$ assay can simultaneously measure sIgG4 against 42 important allergens, and this assay can be performed with very small amounts of serum.

sIgG4 is widely used as a biomarker for immunotherapy, ${ }^{10}$ and its level increases during immunotherapy. Therefore, it is considered as a compliance marker of immunotherapy, ${ }^{10}$ and because an increase in SIgG4 is associated with a beneficial effect in immunotherapy, a low sIgG4 level is a predictor of a poor immunotherapeutic effect. ${ }^{10}$ However, in immunotherapy with multiple allergens, multiple ImmunoCAP ${ }^{\circledR}$ tests are needed to measure the sIgG4 levels of each allergen, making the cost of the assay relatively high. On the contrary, a single test with PROTIA $^{\text {TM }}$ Specific IgG4 ${ }^{\circledR}$ can simultaneously quantify the sIgG4 levels of multiple allergens. This assay can measure sIgG4 levels against allergens commonly used for immunotherapy, including house dust mites, birch pollen, oak pollen, ragweed pollen, mugwort pollen, cat dander, dog dander, Alternaria alternata spores, bee venom, egg, milk, and peanut. Therefore, PROTIA $^{\mathrm{TM}}$ Specific IgG4 ${ }^{\circledR}$ is appropriate for observing the progress of immunotherapy for multiple allergens. Multiple allergen 

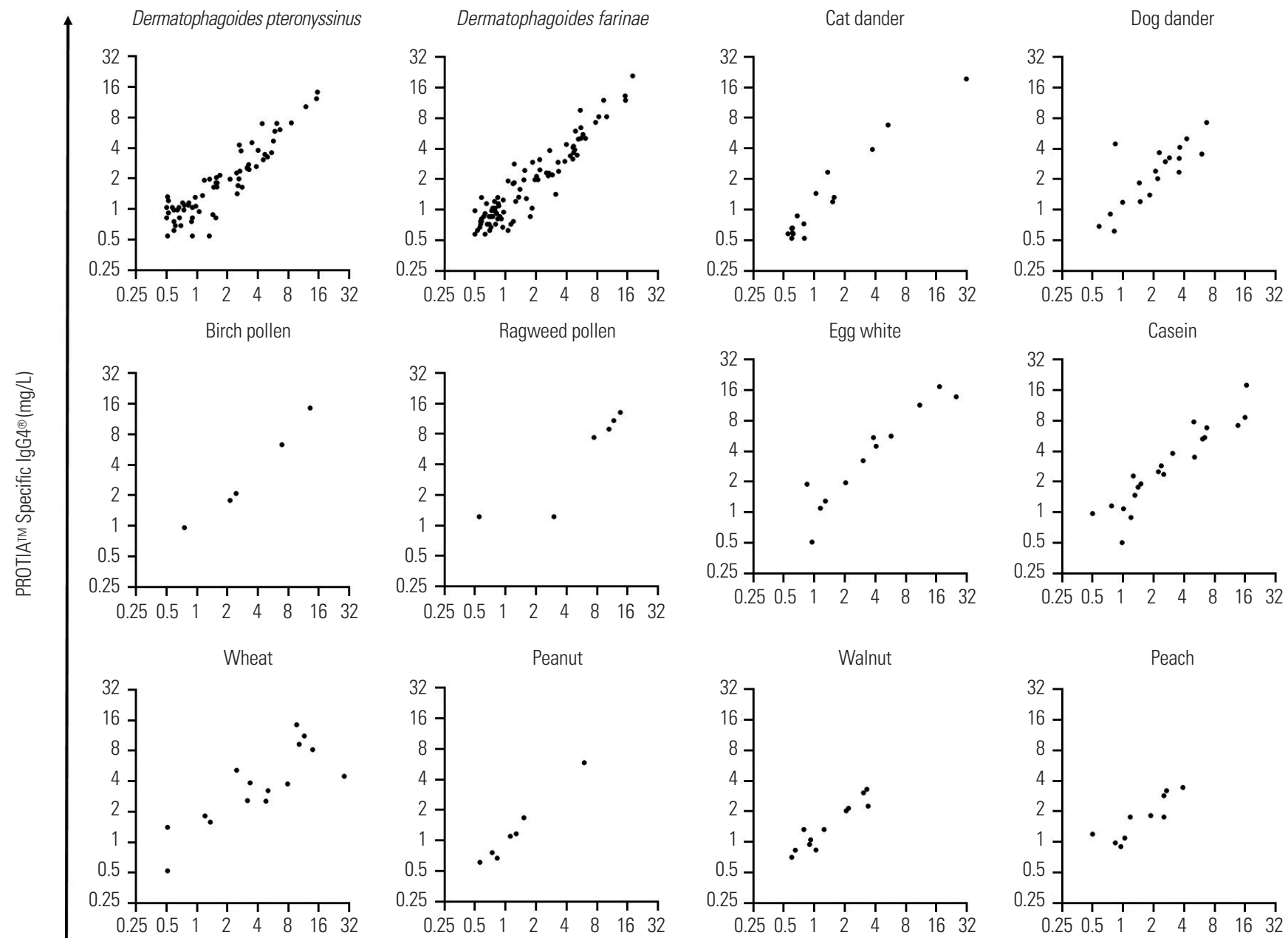

ImmunoCAP® $(\mathrm{mg} / \mathrm{L})$

Fig. 1. Measured slgG4 values for 12 allergens that were positive in both ImmunoCAP ${ }^{\circledR}$ and PROTIA ${ }^{\mathrm{TM}}$ Specific $\lg \mathrm{G}^{\circledR}$.

Table 4. Quantitative Comparison between ImmunoCAP ${ }^{\circledR}$ and PROTIA ${ }^{\mathrm{TM}}$ Specific $\lg \mathrm{G}^{\circledR}{ }^{\circledR}$

\begin{tabular}{|c|c|c|c|c|}
\hline Allergens & Number of cases & Correlation coefficient value & Degree of correlation & $p$ value \\
\hline Dermatophagoides pteronyssinus & 69 & 0.9651 & Very strong & $<0.001$ \\
\hline Dermatophagoides farinae & 89 & 0.9582 & Very strong & $<0.001$ \\
\hline Cat dander & 16 & 0.8400 & Strong & $<0.001$ \\
\hline Dog dander & 20 & 0.8014 & Strong & $<0.001$ \\
\hline Birch pollen & 5 & 1.0000 & Very strong & 0.017 \\
\hline Ragweed pollen & 6 & 0.9856 & Very strong & 0.006 \\
\hline Egg white & 12 & 0.9441 & Very strong & $<0.001$ \\
\hline Casein & 21 & 0.9494 & Very strong & $<0.001$ \\
\hline Wheat & 15 & 0.8097 & Strong & $<0.001$ \\
\hline Peanut & 7 & 0.9643 & Very strong & 0.003 \\
\hline Walnut & 12 & 0.9037 & Very strong & $<0.001$ \\
\hline Apple & 6 & 0.6571 & Moderate & 0.175 \\
\hline Peach & 10 & 0.8811 & Strong & 0.001 \\
\hline
\end{tabular}

Positive results in both tests were compared through correlation analysis. A slgG4 value $\geq 0.50 \mathrm{mg} / \mathrm{L}$ was considered a positive result. Correlation coefficient values were categorized as very strong (0.90-1.00), strong (0.70-0.89), moderate (0.40-0.69), weak (0.10-0.39), or negligible correlations (0.00-0.09). 
immunotherapy is especially popular in the US where the mean number of prescribed allergens is about $8 .^{20}$

sIgG4 is an important marker for food allergy immunotherapy. ${ }^{21}$ Although it is unclear whether IgG4 is directly linked to the development of tolerance to food allergens, ${ }^{22}$ food allergen immunotherapy is often associated with an increase in sIgG4 and a reduction in $\operatorname{sgE}{ }^{23}$ and high sIgG4 and low sIgE levels have been reported to be associated with food allergy tolerance. ${ }^{21}$ Furthermore, patients with food allergy who test positive have a

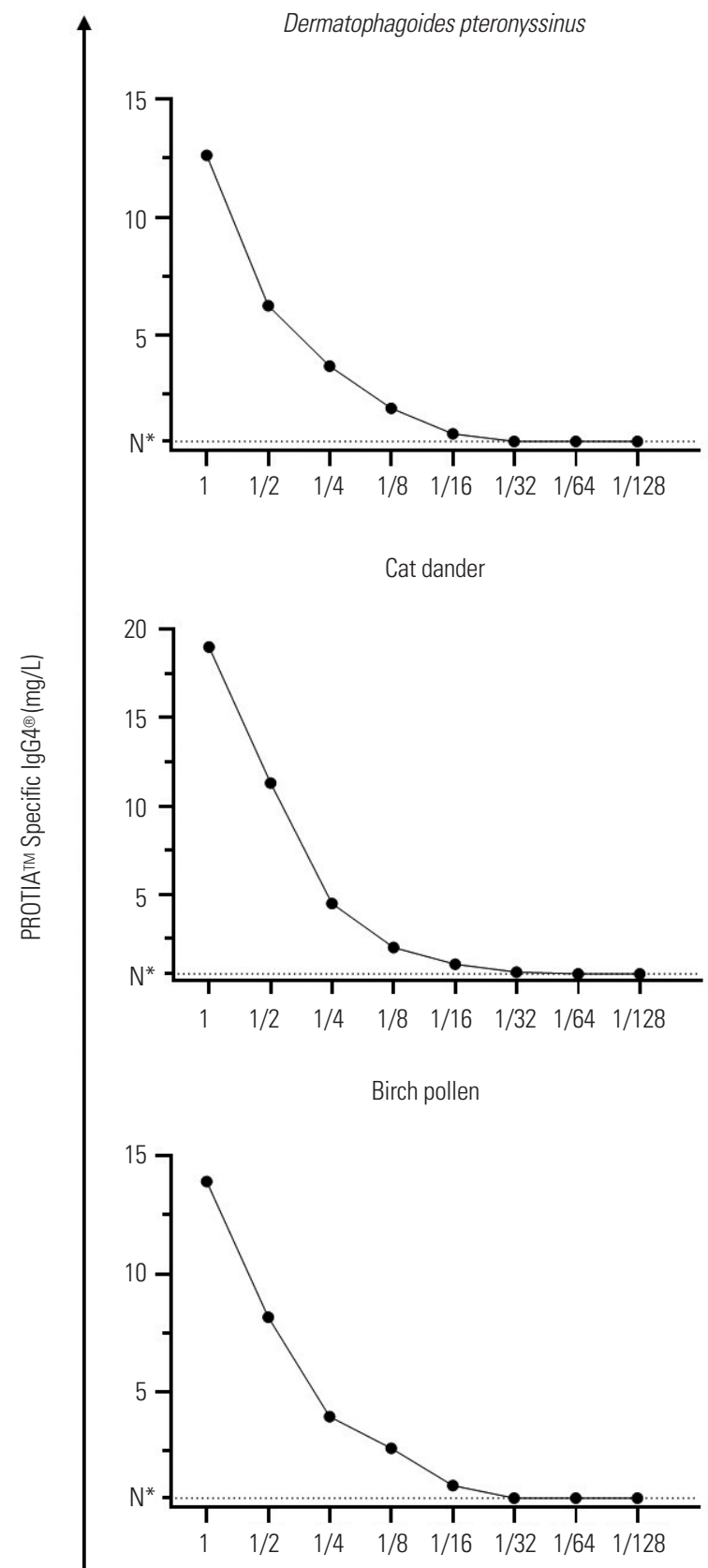

higher sIgE/sIgG4 than those who test negative during DBPCFC. ${ }^{8}$ Therefore, sIgG4 is used as an immune tolerance biomarker for food allergy. ${ }^{21}$ However, patients with food allergy are often sensitized to multiple allergens. Lee, et al. ${ }^{24}$ reported that adult patients with food allergy are allergic to more than two culprit food allergen, and Wang ${ }^{25}$ reported that pediatric patients are allergic to three to four culprit food allergens. In addition, because pollen-food allergy syndrome is often associated with pollinosis patients, ${ }^{26,27}$ sIgG4 levels of several food aller-
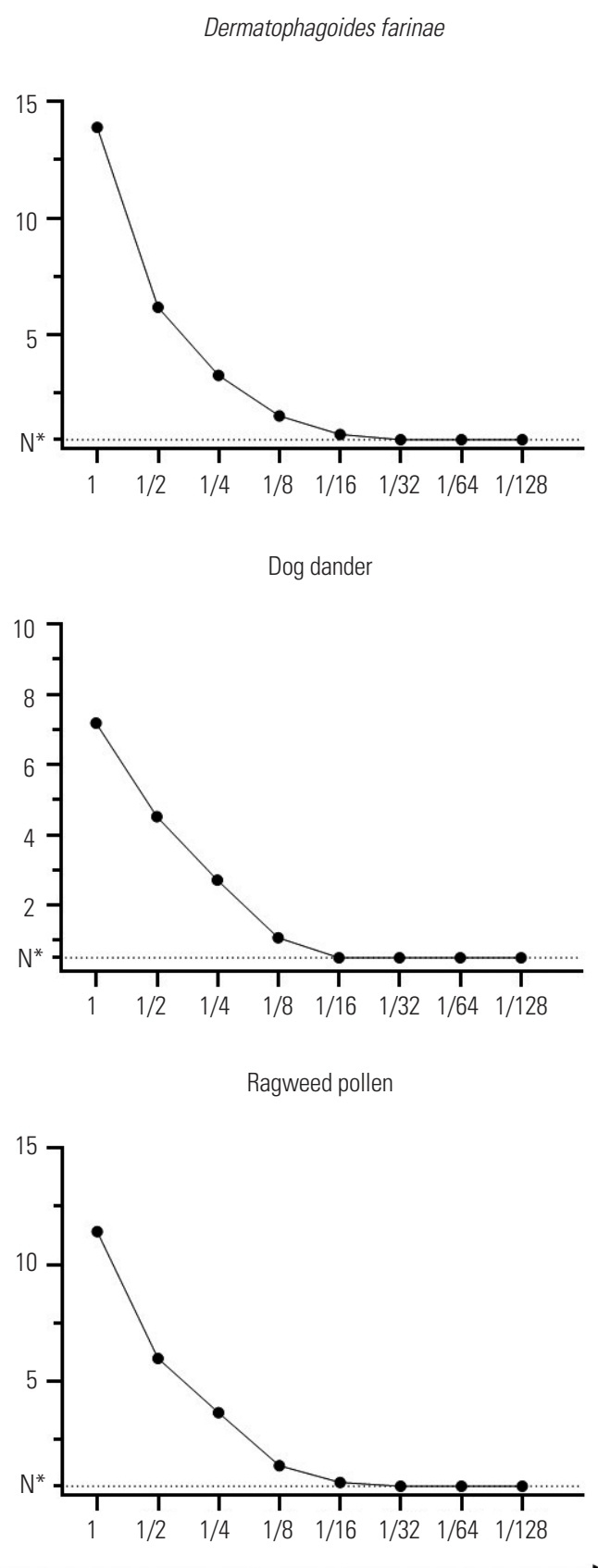

Dilution

Fig. 2. Serial dilution tests performed using PROTIA ${ }^{\mathrm{TM}}$ Specific IgG4 $4^{\circledR}$. Patient sera were diluted with immunoglobulin-depleted serum. $\mathrm{N}^{*}$ : negative. Specific $\lg G 4<0.50 \mathrm{mg} / \mathrm{L}$ is considered a negative result. 
gens might need to be tested during pollen immunotherapy. Therefore, there is a limit in measuring sIgG4 with a singleplex assay. Because PROTIA ${ }^{\text {TM }}$ Specific IgG $4^{\circledR}$ can measure 26 food allergens, this assay can be applied to monitor immunotherapy for food allergy patients with multiple culprit allergens or to predict the tolerance status of those patients.

Meanwhile, sIgG4 may play a vicious role in other diseases. sIgG4 is associated with eosinophilic esophagitis, and the level of tissue IgG4 correlates with the severity of eosinophilic esophagitis and tissue eosinophilia, suggesting the harmful role of sIgG4 in this disease. ${ }^{28,29}$ Identification of the culprit allergen by measuring sIgE and quantifying sIgG4 levels may help diagnose and treat patients with eosinophilic esophagitis. ${ }^{30}$ Culprit food allergens for eosinophilic esophagitis are usually many, including common food allergens, such as milk, egg, wheat, soy, and seafood. ${ }^{31}$ Identification of culprit inhalant allergens may also be important in eosinophilic esophagitis, because accompanying sensitization to inhalant allergens is common. ${ }^{32}$ Oral allergy syndrome can also induce eosinophilic esophagitis, ${ }^{33}$ and oral immunotherapy for food and sublingual immunotherapy for inhalant allergens may also cause eosinophilic esophagitis. ${ }^{34,35}$ sIgG4 concentrations against these food and inhalant allergens can simultaneously be determined using PROTIA ${ }^{\mathrm{TM}}$ Specific IgG4 ${ }^{\circledR}$. Therefore, this assay is potentially applicable to patients with eosinophilic esophagitis.

Another disease where IgG4 may have a pathologic role is IgG4-related disease, which is characterized by a systemic fibroinflammatory condition with an elevated serum total IgG4 level and the accumulation of IgG4-positive plasma cells in the affected organs. ${ }^{17}$ In general, total serum IgG4 levels are measured to diagnose IgG4-related disease.$^{36}$ Culver, et al. ${ }^{37}$ also reported that food SIgG4 is elevated in IgG4-related disease. However, the association between food sIgG4 and IgG4-related disease remains unknown. Therefore, the applicability of PRO$\mathrm{TIA}^{\mathrm{TM}}$ Specific IgG4 ${ }^{\circledR}$ in IgG4-related disease is uncertain.

PROTIA $^{\text {TM }}$ Specific IgG4 ${ }^{\circledR}$ may be applicable to patients with Crohn's disease, for whom dietary restrictions are recommended. Crohn's disease is an inflammatory bowel disease primarily affecting the ileum and colon..$^{38}$ Dietary restrictions help treat some patients with this disease ${ }^{39}$ However, the complexity of dietary restrictions makes it difficult for patients. A previous study reported an improvement in symptoms and a reduction in the erythrocyte sedimentation rate among patients on a targeted exclusion diet by quantifying sIgG4 levels. ${ }^{40}$ Therefore, PROTIA ${ }^{\mathrm{TM}}$ Specific IgG4 ${ }^{\circledR}$ might be applied to determine which foods to restrict. Similarly, dietary restrictions are effective in cases of irritable bowel syndrome, ${ }^{41}$ wherein sIgG4 levels are increased. ${ }^{42} \mathrm{Zar}$, et al. ${ }^{42}$ reported that dietary restrictions based on food sIgG4 are effective. However, further well designed studies are required to confirm the clinical significance of sIgG4 measurement and sIgG4-based dietary restrictions in these diseases.

There are limitations in this study. First, an sIgG4 level less than $0.50 \mathrm{mg} / \mathrm{L}$ was considered a negative titer in this study. Since IgG production is associated with a normal immune response to allergens, ${ }^{43}$ it is difficult to determine the clinical negative value, which may be quite different for each food or inhalant allergen. Therefore, $0.50 \mathrm{mg} / \mathrm{L}$ was considered as the threshold according to the detection limit of PROTIA ${ }^{\mathrm{TM}}$ Specific IgG4 $4^{\circledR}$. Further studies are required to determine the negative reference values of sIgG4 in healthy subjects and patients. Second, some allergens, such as walnut and shrimp in qualitative comparison and apple in quantitative comparison, showed relatively low agreement rates. This might be associated with the small sample size. There is also a possibility of kit inaccuracy. Considering that both assays were not compared for all measurable allergens, additional testing is needed. However, the most important inhalant allergens during immunotherapy, including house dust mites, birch, oak, ragweed, mugwort pollens, and Alternaria alternata spores, showed high agreement rates, and common culprit food allergens, including egg white, casein, milk, crab, wheat, peanut, and peach, also showed high agreement rates. Therefore, we think that the potential applicability of PROTIA ${ }^{\mathrm{TM}}$ Specific IgG ${ }^{\circledR}$ for measuring sIgG4 in allergic diseases was adequately validated.

In conclusion, PROTIA ${ }^{\mathrm{TM}}$ Specific IgG4 ${ }^{\circledR}$, a multiple sIgG4 measurement assay, showed a high consistency with ImmunoCAP ${ }^{\circledR}$ in quantifying sIgG4 levels. This assay is suitable for various clinical applications, especially in multiple allergen immunotherapy and food allergy patients with multiple culprit allergens.

\section{ACKNOWLEDGEMENTS}

This work was supported by the Technology development Program (S2468005) funded by the Ministry of SMEs and Startups (MSS, Korea).

Sung-Ryeol Kim and Kyung Hee Park have no potential conflicts of interest to disclose. Ji Eun Lee is a research scientist at ProteomeTech Inc. Bum Joon Kim is a research scientist at ProteomeTech Inc. Kook Jin Lim is President of ProteomeTech Inc. Jung-Won Park is a shareholder of ProteomeTech Inc.

\section{AUTHOR CONTRIBUTIONS}

Conceptualization: Bum Joon Kim, Kook Jin Lim, and Jung-Won Park. Data curation: Sung-Ryeol Kim, Kyung Hee Park, and Ji Eun Lee. Formal analysis: Sung-Ryeol Kim and Ji Eun Lee. Funding acquisition: Bum Joon Kim, Kook Jin Lim, and Jung-Won Park. Investigation: Sung-Ryeol Kim and Kyung Hee Park. Methodology: Sung-Ryeol Kim and Jung-Won Park. Project administration: Jung-Won Park. Resources: Kook Jin Lim and Jung-Won Park. Software: Kook Jin Lim and Jung-Won Park. Supervision: Kook Jin Lim and Jung-Won Park. Validation: Sung-Ryeol Kim, Kyung Hee Park, and Ji Eun Lee. Visualization: Sung-Ryeol Kim. Writing—original draft: Sung-Ryeol Kim. Writing_review \& editing: Kyung Hee Park and Jung-Won Park. Approval of final manuscript: all authors. 


\section{ORCID iDs}

Sung-Ryeol Kim Kyung Hee Park Ji Eun Lee Bum Joon Kim Kook Jin Lim Jung-Won Park https://orcid.org/0000-0001-7418-0049 https://orcid.org/0000-0003-3605-5364 https://orcid.org/0000-0002-5085-4069 https://orcid.org/0000-0002-7051-3528 https://orcid.org/0000-0001-7099-3237 https://orcid.org/0000-0003-0249-8749

\section{REFERENCES}

1. Schroeder HW Jr, Cavacini L. Structure and function of immunoglobulins. J Allergy Clin Immunol 2010;125(2 Suppl 2):S41-52.

2. French MA, Harrison G. Serum IgG subclass concentrations in healthy adults: a study using monoclonal antisera. Clin Exp Immunol 1984;56:473-5.

3. Aalberse R. The role of IgG antibodies in allergy and immunotherapy. Allergy 2011;66 Suppl 95:28-30.

4. Nirula A, Glaser SM, Kalled SL, Taylor FR. What is IgG4? A review of the biology of a unique immunoglobulin subtype. Curr Opin Rheumatol 2011;23:119-24.

5. Schuurman J, Van Ree R, Perdok GJ, Van Doorn HR, Tan KY, Aalberse RC. Normal human immunoglobulin G4 is bispecific: it has two different antigen-combining sites. Immunology 1999;97:693-8.

6. Davies AM, Sutton BJ. Human IgG4: a structural perspective. Immunol Rev 2015;268:139-59.

7. Djurup R, Osterballe O. IgG subclass antibody response in grass pollen-allergic patients undergoing specific immunotherapy. Prognostic value of serum IgG subclass antibody levels early in immunotherapy. Allergy 1984;39:433-41.

8. Noh G, Ahn HS, Cho NY, Lee S, Oh JW. The clinical significance of food specific IgE/IgG4 in food specific atopic dermatitis. Pediatr Allergy Immunol 2007;18:63-70.

9. Song Y, Wang J, Leung N, Wang LX, Lisann L, Sicherer SH, et al. Correlations between basophil activation, allergen-specific IgE with outcome and severity of oral food challenges. Ann Allergy Asthma Immunol 2015;114:319-26.

10. Shamji MH, Kappen JH, Akdis M, Jensen-Jarolim E, Knol EF, Kleine-Tebbe J, et al. Biomarkers for monitoring clinical efficacy of allergen immunotherapy for allergic rhinoconjunctivitis and allergic asthma: an EAACI Position Paper. Allergy 2017;72:1156-73.

11. Okamoto S, Taniuchi S, Sudo K, Hatano Y, Nakano K, Shimo T, et al. Predictive value of IgE/IgG4 antibody ratio in children with egg allergy. Allergy Asthma Clin Immunol 2012;8:9.

12. Clayton F, Fang JC, Gleich GJ, Lucendo AJ, Olalla JM, Vinson LA, et al. Eosinophilic esophagitis in adults is associated with IgG4 and not mediated by IgE. Gastroenterology 2014;147:602-9.

13. Van Helden PM, van den Berg HM, Gouw SC, Kaijen PH, Zuurveld MG, Mauser-Bunschoten EP, et al. IgG subclasses of anti-FVIII antibodies during immune tolerance induction in patients with hemophilia A. Br J Haematol 2008;142:644-52.

14. Iizuka A, Nagao T. Analysis of IgG heavy chain subclasses of alloantibodies to factor IX by crossed immunoelectrophoresis of factor IX using the intermediate gel technique. Br J Haematol 1983;53:687-8.

15. Van Schouwenburg PA, Krieckaert CL, Nurmohamed M, Hart M, Rispens T, Aarden L, et al. IgG4 production against adalimumab during long term treatment of RA patients. J Clin Immunol 2012; 32:1000-6.

16. Adjobimey T, Hoerauf A. Induction of immunoglobulin G4 in human filariasis: an indicator of immunoregulation. Ann Trop Med Parasitol 2010;104:455-64.

17. Stone JH, Zen Y, Deshpande V. IgG4-related disease. N Engl J Med
2012;366:539-51.

18. Landis JR, Koch GG. The measurement of observer agreement for categorical data. Biometrics 1977;33:159-74.

19. Schober P, Boer C, Schwarte LA. Correlation coefficients: appropriate use and interpretation. Anesth Analg 2018;126:1763-8.

20. Cox L, Jacobsen L. Comparison of allergen immunotherapy practice patterns in the United States and Europe. Ann Allergy Asthma Immunol 2009;103:451-59.

21. Wan KS, Wu HL, Yang W, Wu KG, Wu TC, Hwang B. The critical role of allergen-specific IgE, IgG4 and IgA antibodies in the tolerance of IgE-mediated food sensitisation in primary school children. Food Agr Immunol 2012;23:93-8.

22. Van de Veen W, Akdis M. Role of IgG4 in IgE-mediated allergic responses. J Allergy Clin Immunol 2016;138:1434-5.

23. Tang ML, Martino DJ. Oral immunotherapy and tolerance induction in childhood. Pediatr Allergy Immunol 2013;24:512-20.

24. Lee SC, Kim SR, Park KH, Lee JH, Park JW. Clinical features and culprit food allergens of Korean adult food allergy patients: a cross-sectional single-institute study. Allergy Asthma Immunol Res 2019;11:723-35.

25. Wang J. Management of the patient with multiple food allergies. Curr Allergy Asthma Rep 2010;10:271-7.

26. Kim MA, Kim DK, Yang HJ, Yoo Y, Ahn Y, Park HS, et al. Pollenfood allergy syndrome in Korean pollinosis patients: a nationwide survey. Allergy Asthma Immunol Res 2018;10:648-61.

27. Kim M, Ahn Y, Yoo Y, Kim DK, Yang HJ, Park HS, et al. Clinical manifestations and risk factors of anaphylaxis in pollen-food allergy syndrome. Yonsei Med J 2019;60:960-8.

28. Wright BL, Kulis M, Guo R, Orgel KA, Wolf WA, Burks AW, et al. Food-specific IgG4 is associated with eosinophilic esophagitis. J Allergy Clin Immunol 2016;137(2 Suppl):Ab232.

29. Rosenberg CE, Mingler MK, Caldwell JM, Collins MH, Fulkerson PC, Morris DW, et al. Esophageal IgG4 levels correlate with histopathologic and transcriptomic features in eosinophilic esophagitis. Allergy 2018;73:1892-901.

30. Wright BL, Kulis M, Guo R, Orgel KA, Wolf WA, Burks AW, et al. Food-specific IgG4 is associated with eosinophilic esophagitis. J Allergy Clin Immunol 2016;138:1190-2.

31. Kagalwalla AF, Sentongo TA, Ritz S, Hess T, Nelson SP, Emerick $\mathrm{KM}$, et al. Effect of six-food elimination diet on clinical and histologic outcomes in eosinophilic esophagitis. Clin Gastroenterol Hepatol 2006;4:1097-102.

32. Ridolo E, Montagni M, Olivieri E, Rogkakou A, De'Angelis GL, Canonica GW. Eosinophilic esophagitis: which role for food and inhalant allergens? Asia Pac Allergy 2012;2:237-41.

33. Elhassan A, Mahdavinia M, Bishehsari F, Ditto AM. Strong association of eosinophilic esophagitis and oral allergy syndrome: evidence suggestive of oral route of sensitization to common foodpollen allergens. Am J Gastroenterol 2015;110:S705.

34. Lucendo AJ, Arias A, Tenias JM. Relation between eosinophilic esophagitis and oral immunotherapy for food allergy: a systematic review with meta-analysis. Ann Allergy Asthma Immunol 2014; 113:624-9.

35. Miehlke S, Alpan O, Schröder S, Straumann A. Induction of eosinophilic esophagitis by sublingual pollen immunotherapy. Case Rep Gastroenterol 2013;7:363-8.

36. Xu WL, Ling YC, Wang ZK, Deng F. Diagnostic performance of serum IgG4 level for IgG4-related disease: a meta-analysis. Sci Rep 2016;6:32035.

37. Culver EL, Vermeulen E, Makuch M, van Leeuwen A, Sadler R, Cargill T, et al. Increased IgG4 responses to multiple food and animal antigens indicate a polyclonal expansion and differentiation of pre-existing B cells in IgG4-related disease. Ann Rheum Dis 
2015;74:944-7.

38. Rioux JD, Xavier RJ, Taylor KD, Silverberg MS, Goyette P, Huett A, et al. Genome-wide association study identifies new susceptibility loci for Crohn disease and implicates autophagy in disease pathogenesis. Nat Genet 2007;39:596-604.

39. Levine A, Wine E, Assa A, Sigall Boneh R, Shaoul R, Kori M, et al. Crohn's disease exclusion diet plus partial enteral nutrition induces sustained remission in a randomized controlled trial. Gastroenterology 2019;157:440-50.

40. Rajendran N, Kumar D. Food-specific IgG4-guided exclusion diets improve symptoms in Crohn's disease: a pilot study. Colorec- tal Dis 2011;13:1009-13.

41. Shepherd SJ, Parker FC, Muir JG, Gibson PR. Dietary triggers of abdominal symptoms in patients with irritable bowel syndrome: randomized placebo-controlled evidence. Clin Gastroenterol Hepatol 2008;6:765-71.

42. Zar S, Mincher L, Benson MJ, Kumar D. Food-specific IgG4 antibody-guided exclusion diet improves symptoms and rectal compliance in irritable bowel syndrome. Scand J Gastroenterol 2005;40:800-7.

43. Gocki J, Bartuzi Z. Role of immunoglobulin G antibodies in diagnosis of food allergy. Postepy Dermatol Alergol 2016;33:253-6. 